\title{
What's Wrong with Contemporary Economics?
}

\author{
PAUL P. STREETEN
}

\begin{abstract}
It is argued that in educating economists we should sacrifice some of the more technical aspects of economics (which can be learned later), in favour of the compulsory inclusion of (a) philosophy, (b) political science and (c) economic history. Three reasons for interdisciplinary studies are given. In the discussion of the place of mathematics in economics fuzziness enters when the symbols $a, b, c$ are identified with individuals, firms, or farms. The identification of the precise symbol with the often ambiguous and fuzzy reality, invites lack of precision and blurs the concepts. If the social sciences, including economics, are regarded as a "soft" technology compared with the "hard" technology of the natural sciences, development studies have been regarded as the soft underbelly of "economic science". In development economics the important question is: what are the springs of development? We must confess that we cannot answer this question, that we do not know what causes successful development.
\end{abstract}

"Economics used to be written in English by Scotsmen; today it is written in mathematics by Hungarians". Overheard in the Common Room.

If you can analyse - and not make models your master;

If you can think - and not make algebra your aim;

If you do not consider plain words a disaster

And treat words, figures, symbols all the same;

If you can talk to crowds and keep your virtue

Or walk with econometricians-nor lose the common touch;

If neither facts nor theories can hurt you

If all costs count with you, but none too much

If you can fill the unforgiving minute

With sixty seconds' worth of distance run

Yours is the Earth and everything that's in it,

And - what is more-you'll have a lot of fun!

(With apologies to Rudyard Kipling.)

\section{EDUCATING ECONOMISTS}

The question in the title of this essay is open to two opposite interpretations, one implying approval, the other criticism. It can be interpreted either in an

Paul P. Streeten is Chairman of the Editorial Board of World Development and Professor Emeritus, Department of Economics, Boston University, USA. 
aggressively defiant, pugnacious mode: what's wrong with contemporary economics? The implication would be that everything is for the best in this best of all possible worlds, or at least for the second best in this best of all feasible worlds. Or it can be interpreted in a matter-of-fact, quietly inquisitive mode: what $i s$ wrong with contemporary economics? I shall opt for the second interpretation.

Most of us would agree that he is a poor economist who is only an economist. Yet, the pressures for appointments, promotion, tenure, and publication have become such that economists have to cultivate ever narrower fields, if not little patches. As a result, they tend to become narrow-minded specialists, without training in the understanding of institutions, of the history of economic thought, of economic literature, of the handling and evaluation of quantitative and non-quantitative data, of how to weigh evidence, and without wider visions. And frequently they are not able to communicate even their narrow vision successfully. In his obituary of Frank Ramsey, J. M. Keynes wrote "If he had followed the easier path of mere inclination, I am not sure that he would not have exchanged the tormenting exercises of the foundations of thought and of psychology, where the mind tries to catch its own tail, for the delightful paths of our own most agreeable branch of the moral sciences, in which theory and fact, intuitive imagination and practical judgment, are blended in a manner conformable to the human intellect". Economics has strayed a long way from those delightful paths since Keynes wrote this.

In his essay on Alfred Marshall, Keynes wrote: "The study of economics does not seem to require any specialised gifts of an unusually high order. Is it not, intellectually regarded, a very easy subject compared with the higher branches of philosophy and pure science? Yet good, or even competent, economists are the rarest of birds. An easy subject, at which very few excel! The paradox finds its explanation, perhaps, in that the master-economist must possess a rare combination of gifts. $\mathrm{He}$ must reach a high standard in several different directions and must combine talents not often found together. He must be mathematician, historian, statesman, philosopher - in some degree. He must understand symbols and speak in words. He must contemplate the particular in terms of the general, and touch abstract and concrete in the same flight of thought. He must study the present in the light of the past for the purposes of the future. No part of man's nature or his institutions must lie entirely outside his regard. He must be purposeful and disinterested in a simultaneous mood; as aloof and incorruptible as an artist, yet sometimes as near the earth as a politician".

Undergraduate and graduate education has moved a long way from these types of skill. Judged by its own criteria, it can be said to be a great success. Most members of the profession think they are making important contributions. Economists can get good jobs and are sought after, the discipline attracts good minds, is rigorous and unified, and, in spite of occasional sniping from the outside, is widely admired. Yet, there is considerable unease, both inside and outside the 
profession, expressed by its most senior members in Presidential addresses and on similar ceremonial occasions. Among them is Kenneth Boulding, Ragnar Frisch, Wassily Leontief, David Worswick, Henry Phelps Brown, Lawrence Klein, and G. S. L. Shackle. The critique is summed up in Kenneth Boulding's statement that modern economics is "the celestial mechanics of a non-existent world".

The Commission on Graduate Education in Economics, consisting of very distinguished American mainstream economists, reported in 1991 that tools and theory were emphasised in graduate education at the expense of "creativity" and problem-solving; and that the principal weakness of graduate education was an underemphasis of the linkages between tools, both theoretical and econometric, and real world problems. Graduate students who come to economics from other fields can obtain PhDs with little or no knowledge of economic problems and institutions. There were also criticisms of the lack of writing and communication skills of many graduate students. "The weakness [of graduate education in economics] is not an excessive use of mathematics. If there is a central theme to our concerns, it is that we believe there is considerable scope for improvement in ensuring that students' knowledge of economic problems and institutions enables them to use their tools and techniques on important problems" (pp. 1039-1040).

My criticisms, like those of the Commission, do not apply so much to excessive teaching of mathematics (although it can crowd out other activities and interests, and be quite useless in the later career of the student, especially if he or she seeks a nonacademic job), but, as David Colander has pointed out, to what is left out and to what is illegitimately appropriated. Arrogance (often combined with a feeling of inferiority vis à vis mathematicians and physicists) with respect to a lack of awareness of these limitations may be a tolerable flaw, but intolerance of any other approaches commonly found, whether alternative or complementary to the orthodox approach, is not. Scholars should be, above all, open-minded and tolerant and, if possible, also humble.

What is left out of the curriculum can be divided into areas from inside and outside economics. Inside economics, the study of institutions, economic literature, the history of economic thought, the interpretation of quantitative and qualitative data, how to weigh evidence, and economic history are neglected. Outside economics, philosophy, politics, history, anthropology are candidates for inclusion.

Those of us who accept Keynes's descriptions (or are they prescriptions?) of economics and economists may reflect on what type of education is most conducive to producing a good economist. I suggest that we should sacrifice some of the more technical aspects of economics, on which graduate education so much insists (which can be learned later), in favour of the compulsory inclusion of (a) philosophy, (b) political science, and (c) economic history. Although each of these disciplines has its own justification, I shall argue for them on the narrower ground that they are essential for making a better economist. If we also get in the process more civilised human beings, this is a bonus. Let me say a few words about each. 
Philosophy consists of logic and epistemology, and of moral and political philosophy. A good grounding in logic and the theory of knowledge will make the economist a better economic theorist. The distinction between an identity and an equality (because of the identity of indiscernibles, equality is possible only between non-identicals), elementary to a philosopher, would have saved many pages of print in the early controversy over savings and investment. It is amazing how much wasted effort could have been avoided, had the disputants been aware of the significance of the third little stroke, added to the equality symbol. The philosophical analysis of causality is another area from which economists (and economic statisticians) would benefit. There was an article, I think in Econometrica, or in the Southern Economic Journal, not to be taken entirely seriously, proving that business cycles cause sun spots.

A training in logic would teach students to distinguish between, on the one hand, tautologies and deductions from axioms, which may be valid or invalid, and, on the other, empirical facts and their relation, which may be true or untrue. Mistaking validity for truth and the easy transition from tautology to falsehood (e.g., the Laffer curve, some treatments of utility and profit maximisation) are frequently the bane in economics. It also lies at the heart of the alleged precision and rigour (a friend of mine used to call it rigor mortis) of mathematical economics. Conclusions may be valid but are frequently untrue.

A good education in moral and political philosophy would avoid, or at least reduce, the all too numerous hidden biases in economic reasoning, the smuggled-in value premises, and the frequent naturalistic fallacies (the jump from an "is" to an "ought"). Again, it would save reams of wasted disputations. So I conclude, for knowing philosophy, the economist becomes a better economic theorist.

In 1982 an exchange took place between the Nobel Laureate and Yale Professor James Tobin and the Harvard philosopher, sometimes called the rich man's Rawls, Robert Nozick on "social justice in the Reagan era". Tobin said: "There's nothing more dangerous than a philosopher who's learned a little bit of economics". To this Nozick immediately responded: "Unless it's an economist who hasn't learned any philosophy". On this occasion, I confess, I agree with Nozick.

Political science, or, less ambitiously, politics as it is known in England, makes the economist a better applied economist. The knowledge of political institutions and processes, and of political history, makes the economist aware of the constraints and opportunities for getting policies implemented. What I have in mind is not the usurpation and narrowing of political science by economic method (or methodology as it is, regrettably, nowadays always called), as illustrated by the writings of Gary Becker and the Public Choice School, which uses a brain transplant from the narrowest economic doctrines to politics, but its broadening, as was done, for example, by Albert Hirschman, when he enriched economics with political categories by exploring "voice" as an alternative to "exit". 
Thomas Schelling talks of "the absent colleague" when it comes to applying economic advice. We economists have to take on ourselves the task of investigating the political variables. And we should supplement the positive political economy by a normative branch, concerned with analysing what pressure groups, what reformist alliances, what types of progressive coalitions, can be mobilised for desirable policies and reforms.

Economists are trained in the study of the operation of economic forces within political, social, and moral constraints. This approach has to be supplemented (and in some cases replaced) by the study of the operation and manipulation of political, social, and psychological forces within economic limits. More fundamentally, the distinction between economic and non-economic variables may not be tenable if the aim is to understand social problems. I shall say more of this below.

The inclusion of some social and economic (as well as political) history needs hardly a defence, although it is sadly neglected. As Andrew Kamarck remarked in a discussion of this subject, economic history calls for a different mind-set from economics. It is not about equilibrium conditions about equilibrium conditions, about how a situation once disturbed returns to its initial state, but about change. Adam Smith did understand the conditions of change, but economists have lost sight of it since.

The discussion of outward-looking versus inward-looking strategies, and of import substitution versus export promotion, would have gained in depth had the participants taken into account the historical phasing of these processes. Every point on our demand and supply diagrams should have an added time dimension, for memories of the past inevitably affect movements from this point to any other. Economists have attempted to deal with expectations, but we still draw demand and supply curves in a timeless fashion. The widely accepted dictum "bygones are bygones" misses entirely the mark, for bygones affect our expectations and therefore current behaviour. So I conclude that the economist, qua economist, is a better theorist for knowing philosophy, and a better applied and empirical economist for knowing political science and history.

Education is, of course, more than acquiring skills or aptitudes; it involves also the acquisition of attitudes. We prefer our students to be not methodologydriven, but reality- and problem-driven; to know the scope, as well as the limits of the techniques we teach them; to have some scepticism and humility, as well as pride in their subject. The brightest will probably acquire these traits in any case. But how do we make the modal men and women use the box of tools with which we equip them properly, and prevent them from falling victim to the law of the hammer, according to which a little boy, given a hammer, finds everything worth pounding, not only nails but also Ming vases? I suggest that the added education in philosophy and politics may also contribute to the right attitudes. 
Does this broadening not mean that we have to sacrifice specialised education in a subject that is all the time becoming more technical, specialised, professional, and fragmented? Unless we lengthen the time of study, clearly some sacrifice is involved. It is to be hoped that mathematics will be taught more effectively in high schools, so that universities can be spared this remedial training. Other more specialised branches, now included in the graduate curriculum, can be acquired later, or may not be necessary for economists entering public administration, the civil society, the media, and business.

When I was a student I went through the Oxford school of PPE, which stands for philosophy, politics, and economics (with an additional paper on social and economic history in the final examination). Since those days the pressures towards specialisation have removed the compulsory philosophy and politics papers and the economic history paper from PPE. I compared my teachers and the successful older generation of economists who had sprung from this education with those who had gone through the then more specialised economics tripos at Cambridge. (Since those days there has been convergence, Oxford giving more specialised options, Cambridge fewer.) And I found that the Oxford products did not lag behind the Cambridge products in professionalism. Comparing only Nobel Prize winners, the score is 2:1 in favour of Oxford: Hicks and Meade were Oxford-trained, Richard Stone was Cambridge-trained. Roy Harrod, a should-have-been Nobel Laureate (someone should publish a Who Should Be Who and perhaps a Who Would Be Who), was Oxford-trained. Keynes himself, a genius, though Cambridge-trained, transcended its educational limitations.

The problem with American undergraduate education is that most American schools (with a few notable exceptions) teach so badly that the young people have to go through remedial training in their early university years. They are often almost illiterate when they enter university. At the same time, these youngsters are often eager to learn, have open minds, and are asking big questions. But while their minds are open and while they are eager to ask these large questions, they do not have the basic training to explore them.

By the time they reach graduate studies, the groundwork has been done, but the need to chase after credits and learn the required techniques tends to drive out time and interest in exploring wider areas, asking interesting questions. As a result, only very few exceptional young people are led to approach the subject with a sense of reality and vision. The majority is stuck in the mould of narrow experts.

There are some signs of a rising demand for a more realistic economics that is more relevant to policy issues. Sniping from the sidelines is done by feminist economists, who emphasise argument by rhetoric, analogy, metaphor, pattern recognition, imagination, and dialectical reasoning against the "rigour" of mathematics and the "hard science" of masculine economics. The "new" institutional economists, the school of experimental economics, some radical economists, and 
others have also criticised the narrowness of mainstream economics. In particular, the environmental economists have questioned the narrowness and the blindness of conventional approaches. But, by and large, they have left the main structure unaffected.

Recently a "Petition to Reform Graduate Education" was signed by 463 American undergraduate economics professors who are involved in hiring new economists. They say that good teachers of undergraduates do not receive currently necessary training in certain fields. Specifically, they would like anyone they hire to have:

(1) a background in the economic debates and literature of the past 20 years and how those debates have shaped what we as a profession believe;

(2) a solid training in the models which they will be teaching to undergraduates;

(3) a knowledge of economic institutions and the role institutions play in the economy;

(4) an ability to communicate orally, and in prose, the central ideas conveyed in introductory and intermediate micro- and macro-economics;

(5) knowledge of the alternative approaches in economics and an ability to compare and contrast different approaches; and

(6) a knowledge of econometrics, but also of the limits of econometric testing.

These characteristics are very rare in the current requirements for academic appointments.

\section{INTERDISCIPLINARY AND MULTIDISCIPLINARY STUDIES}

There are three reasons for interdisciplinary, multidisciplinary, transdisciplinary or supradisciplinary work in economics. Each has different methodological implications. First, specialists in different disciplines may work together on a specific practical problem. Improving nutrition, introducing new varieties of crops, controlling population growth, reducing pollution, planning a new town, may call for drawing on several disciplines and applying their contributions to the problem. In this cooperative effort the disciplines are not transcended but brought together for a practical purpose. This practical need to draw on all relevant disciplines does not affect the methods or the content used in the contributing disciplines. On the contrary, it is just because they are specialists in their fields that the different members of a team have a contribution to make to an integrated solution. We may think of them as members of a Royal Commission or a Presidential Task Force, investigating problems of controlling environmental pollution, deciding on a family planning programme, planning a new town, or investigating how to combat hunger. 
This kind of interdisciplinary work, though highly desirable for certain purposes, runs the risk of strengthening disciplinary borders instead of abolishing them. One member of the team provides the economic perspective, another the demographic one, a third the political one, and the result is that each is confirmed in his own territory, without an advance in theoretical knowledge.

Second, it may be the case that certain assumptions, concepts, methods or techniques, hitherto applied only to one area of study, yield illuminating results when applied to another, previously analysed in quite different ways. There has been a considerable invasion of economic concepts and techniques into the territory of political scientists, anthropologists, sociologists, and psychologists. Principal-agent theory, the "new institutional economics", and work on the family, and on racial and gender discrimination, have dealt with areas traditionally discussed by sociologists. The assumption of maximising behaviour under constraints has been fruitful, up to a point, in illuminating the behaviour of consumers, firms, and farms. Its success in these fields has encouraged its application to political activities such as voting, party formation, and government decision-making. Calculations of economic returns and cost-benefit analysis have been extended from profit-seeking investments to education, health, birth control, the allocation of time between work and leisure, and among different leisure activities, decisions about marriage and divorce, the size of the family, and even to extramarital affairs. Occasionally, though much less frequently, concepts used in political theory have been applied to economic problems. Albert Hirschman's use of "voice" as an alternative to "exit" is an example already mentioned.

There is a third, and deeper, reason for interdisciplinary work. It may be that for a particular time or region the justification for having a separate discipline does not hold. This justification for a discipline consists in the contingent fact that between the variables encompassed by this discipline and those treated by another, there are few interactions, and the effects of any existing interactions are weak and dampened. Only then are we justified in analysing causal sequences in one field, without always and fully taking into account those in others.

We may agree that society is a system and that all social phenomena are related, but with growing differentiation of functions and standards, some relationships become stronger than others. This justifies us (some would argue) in, say, separating business responses from family responses, or economics from anthropology. The need for interdisciplinary studies arises not because people in developing countries, particularly in subsistence households, perform many functions normally separated in rich countries, but because there is interdependence between variables normally analysed separately. "Lack of specialisation among the people being studied in no way justifies lack of specialisation among the students. A student of Michelangelo could well confine attention to his sculpture, while caring little for the architecture and painting in which Michelangelo also excelled". The fact 
that functions in developing societies are less differentiated does, of course, have a bearing on the interdependence.

There are numerous illustrations of such interdependence in economics. One is the relationship between income per head and population growth. High or accelerating rates of population growth are often presumed to reduce income per head, and higher income per head may be presumed in certain conditions to reduce population growth. Or consider the relationship, examined by Gunnar Myrdal, between the level of living of a deprived minority group, for example a low caste or a racial minority, and an index of prejudice against it. Prejudice is a function of the level of living - the less educated, the less healthy, the stronger the grounds of prejudice - and the level of living is a function of prejudice - the stronger the prejudice, the stronger discrimination in jobs, education, and so forth. Or consider the relation between productivity per worker and the ratio of investment to income. The higher the productivity, the higher will tend to be the savings and hence the investment ratio, and the higher the investment ratio, the more capital per worker and hence the higher productivity. One could also trace interdependence between the quality of interdisciplinary studies and the quality of the scholars they attract.

If interdependence between variables normally studied separately is strong, or, though weak, if reaction coefficients are large, or, though small in the neighbourhood, if they change size for moves above a critical level, there is a case for breaking down the boundaries between disciplines. This is sometimes called transforming parameters into dependent variables. Family ties and economic calculus, land tenure and responses to incentives, religious beliefs and commercial motivation, prejudice and income level may interact in this way. When interdependence of this kind occurs and when the interdependent variables belong to different disciplines, there is a case for interdisciplinary work.

The third kind of interdisciplinary work, at a deep level, is the most difficult and is best done either under one skull, or by a group of closely associated colleagues who stimulate and complement one another, and have simultaneously a similar basic outlook. Some of the best economic research is a social activity that progresses most rapidly where a small group of like-minded scholars are not at all troubled by being out of the step with the profession as a whole.

It is possible to draw two quite distinct conclusions from such interaction. First, it may be said that what is called for are not interdisciplinary studies, but a new discipline that constructs concepts, builds models (or paradigms, as the current phrase has it), and designs theories appropriate to the conditions of the developing societies. In this case, we may have to discard concepts such as employment, unemployment, underemployment, income, savings, investment, and construct altogether new, more appropriate, concepts. Second, and less radically, the existing concepts, models, and theories may continue to be used, but their content may have to be changed or their definitions modified. 
How would these three approaches to interdisciplinary studies work out between, say, economists and anthropologists? In the first case-the team approach - anthropologists would be used for their traditional training. If a land reform or a family planning programme or a tourist project or even a research project is proposed, they will be able to point to "constraints" in the beliefs and mores of the people, or to beliefs and institutions that can be mobilised and on which the proposed reforms or projects can be built. Nothing new or radical is required here.

The second case is more interesting. I suspect that economic methods could illuminate some anthropological work and probably the converse too. The most interesting possibilities, however, are opened up by the third case, whether in its reformist or radical version. An agricultural production function in many developing countries should count among its inputs not only the conventional economic factors of production, land, labour, fertilisers, equipment, water and power, but also levels of education of the farmers, their nutritional status, their health, their distance from town, systems of land tenure and of family kinship. All these variables are likely, in some societies, to be systematically related to agricultural production.

A status-conscious anthropologist will complain that he is being used only to provide fodder for the cannons of the economist. A self-respecting anthropologist may refuse to have all the important questions asked by the economist and to be reduced to a handmaiden, supplying low-class empirical data for the high-class analytical structure of another discipline.

Questions of status and precedence are, of course, not the concern of serious scholars. But it may turn out that the whole notion of a production function is wrong or misleading. Perhaps there is no systematic relationship between inputs, whether of fertilised, irrigated land, or of physical capital, or of educated farmers and human capital, on the one hand, and crops on the other. It may be that output depends on variables that have been observed and analysed by anthropologists: the relationship between majority and minority groups; religious beliefs, the Protestant ethic; or kinship systems.

Or again, at a different level of discourse, it may be that increases in output beyond a decent minimum are not valued as a crucial component of development. The society may have opted for an alternative style of development, in which the ever-growing production of material goods is rejected. Or, through a shift in valuations, negatively valued unemployment may be converted into positively valued leisure. Or the way in which individual or cooperative agricultural work and its accompanying rites and ceremonies are performed are valued for themselves, not only as means to producing crops. Production and consumption then cease to be distinct spheres. Or the result of any given input could crucially depend on a series of preceding historical events, giving rise to different expectations, and making it quite impossible to draw up a two-dimensional functional relationship. Each point on the supply curve would be located in a different place according to its history. 
If any of this is the case, the crucial questions will have to be asked by the anthropologist or sociologist or historian. He or she has to construct the concepts and it is then the economist's turn to fill the boxes built by the anthropologist, sociologist or historian. Which of these possibilities should be realised will depend partly on empirical conditions, and ultimately on valuations and the choice of life styles.

American education and, I suspect, European education also, is extremely hostile to multi- and interdisciplinary studies, whatever the professions of scholars may be. Charles Roos reported a case that suggested the difficulties of combining mathematics, statistics, and economics. A young economist sought to extend static economic theory into a testable dynamic structure. His paper used technical mathematics and statistics. A leading American economics journal refused to publish the paper unless he removed the mathematics and statistics. A mathematics journal would publish it only without the statistics and economic theory. A statistics journal demanded that he eliminate the mathematics and the economics. The article is nearly fifty years old, but nothing has changed since then, as the following recent experience shows.

I have known of a fine scholar who combined macro-political analysis with village studies and the impact of these on intra-family relations. It was a combination of anthropology, political science, and economics. She was refused tenure at an American university on the ground that the subject did not fit into any single discipline.

Realism would call for all relevant disciplines to be brought to bear on the solution of a problem. Gunnar Myrdal used to say there are not economic and other non-economic problems, there are only problems. "In fact the problems are not economic, social, ecological, psychological, etc., but just problems, intermingled and complicated". Some scholars, mostly of the older generation, have investigated the real world: Herbert Simon, Wassily Leontief, and Albert Hirschman are examples. But few among the younger generation of tenured American economists have followed in their steps.

E. F. M. Durbin, a brilliant British economist who was drowned when young, wrote an article in 1938 in which he pleaded for (1) a union between abstract and empirical research, between theory and observation, and (2) cooperation of economists with specialists from other fields. He found that in pre-war Britain there was no shortage of empirical work. But theoretical and empirical work were done separately and distinctly, without illuminating each other. He quoted the philosopher Immanuel Kant: "Thoughts without content are void; intuitions without conceptions, blind".

In arguing for interdisciplinary work, he says that, of course, subdivisions of an area of work are necessary. But, unlike the natural sciences, the subdivisions in the social sciences are largely abstractions from reality rather than sections of 
reality. Botany is the study of plants, zoology of animals, crystallography of crystals. But economics is the study of the economic aspect of social behaviour, law of the legal aspects, political science of the political aspects, etc. The sub-divisions turn on the definitions of terms and not on sub-divisions inhering in the objects of study. The conclusion does not point to large cooperative teams doing research on a subject. Durbin calls them "white elephants in labour to produce platitudinous mice". We all know that the best interdisciplinary research is carried out under one skull.

The rejection of the need for interdisciplinary studies is another aspect of the turning inwards of modern economics and this is a specifically American feature. The universe is not divided along the same lines as the university. But it is university

departments that dictate what should be incorporated in research, appointments of faculty and their promotion, not the problems of the real world. And the work will be judged, not by criteria of relevance, but by the standards of excellence evolved from within the discipline.

\section{THE USE OF MATHEMATICS}

Frank Hahn, on his retirement, recommended to young economists "to avoid discussions of 'mathematics in economics' like the plague". I shall risk the danger of infection and say something about it.

Paul Samuelson in the Foundations of Economic Analysis quotes J. Willard Gibbs: "Mathematics is a language". There can be no objections to the use of this language or jargon where it is appropriate. But users of it should know its limitations as well as its scope. Some economists and writers of articles should perhaps be reminded that English, also, is a language. The objections to the use of mathematics in economics do not relate to what it includes, but to what it excludes from consideration. The complaint is both about what has to be left out from other disciplines, and about the spread of mathematics beyond its legitimate boundaries. What is needed is addition and containment. Kenneth Boulding has said that "I know of no mathematical expression for the literary expression 'I love you' ". In a more recent paper Boulding wrote: "[mathematics] is a language —or perhaps we should say a jargon - with an extraordinary paucity of verbs - it is hard to think of more than four: equals, is greater than, is less than, and is a fraction of".

It is also true that from its beginnings economics has been couched in formal arguments. The models were often implicit rather than explicit. Even the politician, the official, and the practical man, when putting forward some explanation or recommendation, has some kind of model at the back of his mind. Joan Robinson once said, "I don't know mathematics, therefore I have to think". But it can be rightly argued that it is a virtue to make relationships explicit rather than leave them implicit.

It is often claimed that the virtue of mathematics is that assumptions, deductions, and conclusions are spelt out precisely, whereas verbal economics permits fuzziness. Abstraction is, of course, necessary in all thinking. But not all 
abstractions are equally useful, and some are definitely misleading. Nor is mathematical reasoning exempt from fuzziness. Fuzziness enters into mathematical economics when a,b,c are identified with individuals, firms, or farms. The identification of the precise symbol with the often ambiguous and fuzzy reality, invites lack of precision and blurs the concepts. Mathematical economists are also unrigorous in spelling out what would have to be the case for their exercises to be applicable. There is often a lack of realism in their assumptions. This may be a virtue, for all theory has to abstract, has to leave out many features of a complex reality, but if the abstractions are of the kind that pours out the baby instead of the bath water, it is damaging to an understanding of reality. The accusation that economics is the science that argues from unwarranted assumptions to foregone conclusions then becomes justified.

The correct inference from clearly stated premises leads to valid conclusions. The correct analysis of states and events in the world is called truth. There are two dangers in an over-use of mathematics in economics. First, as we have seen, validity can be mistaken for truth. Deductions from artificial models can be mistaken to be descriptions and analyses of the real world. Secondly, the time and effort devoted to deducing theorems can be at the expense of investigations of real events. The result is the exclusion of certain questions and techniques of understanding the world. There is evidence that economics has suffered from both dangers.

In a frequently quoted passage Alfred Marshall wrote: "In my view every economic fact, whether or not it is of such a nature as to be expressed in numbers, stands in relation as cause and effect to many other facts, and since it never happens that all of them can be expressed in numbers, the application of exact mathematical methods to those which can is nearly always waste of time, while in the large majority of cases it is positively misleading; and the world would have been further on its way forward if the work had never been done at all".

In another letter to Bowley he wrote: "I had a growing feeling in the later years of my work at the subject that a good mathematical theorem dealing with economic hypotheses was very unlikely to be good economics: and I went more and more on the rules - (1) Use mathematics as a shorthand language, rather than as an engine of inquiry. (2) Keep to them until you are done. (3) Translate into English. (4) Then illustrate by examples what are important in real life. (5) Burn the mathematics. (6) If you can't succeed in (4), burn (3). This last I did often".

Keynes, himself no mean mathematician, wrote, “..symbolic pseudomathematical methods of formalising a system of economic analysis....allow the author to lose sight of the complexities and interdependencies of the real world in a maze of pretentious and unhelpful symbols".

Many other distinguished mathematical economists, from Simon Kuznets to Kenneth Arrow, Gerard Debreu, Lawrence Klein, Kenneth Boulding, Ragnar Frisch, E. H. Phelps Brown, David Worswick, and Wassily Leontief have been similarly 
critical of the abuse and excessive use of mathematics in economics. Some of these repent in presidential addresses, but then go away and sin again. The criticism is directed at the triumph of technique over substance, of form over content, of elegance over realism. It is true that mathematics has a simplicity, beauty, and elegance that are seductive. But as contrasted with evolving its own standards of excellence, one may ask: What does it contribute to either understanding, or prediction, or prescription? Mathematics should be the servant of economics, not its master.

Wassily Leontief, in his presidential address to the 1970 meeting of the American Economic Association, condemned "preoccupation with imaginary, hypothetical, rather than with observable reality". In a letter to Science magazine he wrote, "Page after page of professional economic journals are filled with mathematical formulas leading the reader from sets of more or less plausible but entirely arbitrary assumptions to precisely stated but irrelevant theoretical conclusions". As a good empiricist, Leontief then investigated recent articles in The American Economic Review. He found 54 percent of articles were "mathematical models without any data". Another 22 percent drew statistical inferences from data generated for some other purpose. Another 12 percent used analysis with no data. Half of one percent used direct empirical analysis of data generated by the author.

One may be forgiven if one feels some forms of mathematical economics should be an activity permitted only between consenting adults in private, or that it resembles masturbation in that it yields enjoyment to the practitioner without having to make any contact with outside reality.

Yet, it is true that training in mathematics should probably be a condition for a training in economics. The reason for this is that otherwise the economist would not be able to see through the flawed reasoning. When the non-mathematical economist picks up an issue of a current economic journal, he may feel like Diderot at the Court of Catherine the Great when Euler said to him "Sir, $(\mathrm{a}+\mathrm{b}) / \mathrm{n}=\mathrm{x}$, hence God exists; reply!" And, like Diderot, he may slink away in shame. Or (as Samuelson has pointed out), he may disbelieve the next mathematician who later comes along and gives him a true proof of the existence of the Deity.

What are the reasons for this dominance of mathematics, for the priority of form over content, of technique over relevance and realism? Some blame Milton Friedman's 'as if ' doctrine (that assumptions need not, indeed should not, be realistic) and the romantic desire to pass as a scientist. To adapt a term from psychoanalysis, economists suffer from physics envy. At the end of the last century, with the marginal revolution, mathematics was introduced into economics by Walras, Cournot, Jevons, Pigou, Fisher, Edgeworth, and others to make it more like physics, and raise the status of economists. Since then, and particularly since the 1950s, it has come to dominate the subject. 
Some of the reasons are internal, others external. The doctrine of Milton Friedman that lack of realism of assumptions is a virtue has already been mentioned. Lack of realism may have two quite distinct meanings. All thinking and theorising has to select, to abstract, from reality. It is like making a map, which can never incorporate all features of reality. This is its virtue, for without leaving out irrelevant features, we could not find our way and the map would be useless. This type of "distortion" of reality, which selects relevant features and leaves out irrelevant ones, is indeed a virtue.

This is not what Friedman's doctrine says. According to Friedman, only the predictive power of the theory is relevant; if it yields correct prediction, the assumption may be as far removed from reality as we wish, indeed fly in its face. But first, theories may have other functions than prediction; they may explain, illuminate, or prescribe. Second, it is hard to see why incorrect assumptions should yield systematically correct predictions. Be this as it may, the Friedman doctrine was one ground on which mathematical economists could proceed without testing the correspondence of their symbols to real entities.

Among other internal reasons is the already mentioned beauty and elegance of mathematics, the prestige attached to it, and the standards of excellence evolved from within mathematics. But I suggest that among the external reasons there may be one to which little attention has been paid. The political pressures of McCarthyism in the 1950s played, I think, an important part. Economics deals with people's pockets and their ideals: a highly explosive mixture. To be accused of criticising the capitalist system and pandering to socialism was very dangerous in the 50s. Yet, any honest economist looking at the real world would have had to come up with some criticisms. So mathematics provided a safe escape mechanism that drove economists away from political and economic reality.

The proof of the pudding is in the eating. Has mathematics advanced the subject? yielded new insights? provided deeper analysis? contributed to more accurate predictions or better prescriptions and policies? I suggest that, on the whole, and with the exception of some important and applicable insights from game theory, the results have been quite puny compared with the sophistication of the apparatus. Those not able to handle the mechanics of modern mathematical economics may feel like the handloom weavers when the power loom was introduced. But they can find comfort in the fact that the power loom weavers have been weaving the Emperor's clothes.

Martin Hollis once remarked, a man who is trying to find a large piece of buttered toast to sit on is not usually thought to be rational if his action is "rationalised" by being shown to be consistent with his belief that he is a poached egg.

I conclude that mathematics has its place in economics, but that it should be kept in its place. We should use mathematical analysis like grafting body parts onto 
a living body in spare parts surgery. Quantitative and qualitative arguments can then be combined, formal and non-formal methods can be used, historical and anthropological insights can be added, and a fuller understanding can thus be reached.

\section{THE CURRENT STATE OF ECONOMICS}

What is the difference between a specialist and a generalist? According to a well-known quip, the specialist knows more and more about less and less, until he knows everything about nothing; the generalist knows less and less about more and more, until he knows nothing about everything. The real question behind this quip is, should a well-trained economist concentrate on a few areas or spread his research widely?

The obvious answer is that this should be left to the preferences of the individual in question. The spark of good, original work is so rare, that it should be fanned wherever it strikes, whether in a concentrated or diluted form. But there are professional pressures for appointments and promotions that guide a scholar in his preferences. To the question: "What is your field?" the economist eager to advance his career must have an answer. And it is often better for his or her advancement if the field is a little patch.

Modern economics has become too narrow, as well as too far removed from reality. The German word for the product of many economics graduate schools is Fachidiot, the French idiot savant. Robert Kuttner wrote: "Departments of economics are graduating a generation of idiots savants, brilliant at esoteric mathematics yet innocent of actual economic life".

Jacob Viner once said that "men are not narrow in their intellectual interests by nature; it takes special and rigorous training to accomplish that end". And when graduate students were asked in the èlite universities economics departments what they disliked most about their graduate schools, the majority of comments mentioned the heavy load of mathematics and theory and a lack of relevance of the material they were learning.

I agree with Amartya Sen in believing that juggling lots of balls clumsily is superior to displaying virtuosity with only one ball. If this means that some precision may have to be sacrificed, the broad-gauged economist may prefer to be vaguely right to being precisely wrong. If I could choose between being accused of reductionism and fuzziness, I think I would prefer to be accused of fuzziness. Robert Solow said that reductionism is not the occupational disease of economists, it is their occupation. I find this regrettable.

Economics is not a science in which controlled experiments can be conducted. No economic theory has ever been falsified by an experiment.

There is the widespread impression among economists that there is a high degree of consensus on modern economics in the profession. An interesting article 
by Bruno Frey and others tested the degree of consensus and dissensus of economists in different countries. American, Swiss, and German economists tend to support competition and free markets, and hence neoclassical economics, while French and Austrian economists are more inclined to support government interventions. (The Austrian view on these questions is, of course, quite different from the "Austrian" school in economic theory.) The results suggest a good deal of in-breeding among American economists. They mistake their views for generally accepted ones. This is largely the result of the provincialism of American economists, in turn partly the result of the large size of the country. They have little notion of what is being thought and written outside their borders.

Robert Frank and others investigated whether studying economics (in America) inhibits cooperation and makes students less cooperative and more selfinterested. After surveying several other studies and conducting their own, they found that economics students are more self-interested than others, and that it is not self-interested people who are attracted to the study of economics, but it is the study of economics that makes people more self-interested. They conclude that emphasis in teaching on the self-interest model inhibits cooperation. As the authors point out, self-interested responses can be counter-productive. The ultimate victims of noncooperative behaviour may be the very people who practise it. The authors conclude that "economists may wish to stress a broader view of human motivation in their teaching".

A survey by Arjo Klamer and David Colander asked American students at a few top universities what they regarded as the conditions for success in the economics profession. "Knowledge of the economy", "knowledge of economic literature," and "being interested in, and good at, empirical work", ranked low, and in this order from the bottom up ("knowledge of the economy" being the lowest), compared with "being good at problem solving," "excellence in mathematics", "being very knowledgeable about one particular field", again ranked from the top down.

The problem with this narrow, unrealistic, self-satisfied, often intolerant approach to economics is not only that those educated in America and the consumers of their product suffer professional debilitation, but the influence is worldwide. Students from overseas, including many developing countries, if they return to their homes, are imbued with the spirit. But this is not all. Even those who never leave their home countries are powerfully influenced by the thrust of what is being published in the top journals in America. This form of diversion of brain power adds to the losses suffered from the external brain drain (the loss of educated, professional manpower to the rich countries) and may be called the internal brain drain. Its pernicious influences are a multiple of those of the external drain.

There are, however, signs that things may be changing for the better and that the crest of the wave of unreal and escapist economics may be passed. The Journal 
of Economic Perspectives communicates to a wide audience and raises important real world questions. The award of the John Bates Clark Medal to the labour economist David Card from Princeton is one of them. David Card (with Alan Krueger-exLabour Secretary Robert Reich's chief economist) has done important empirical, unconventional work on subjects such as minimum wages and the impact of education on earnings. Another sign is the appearance of articles in the American Economic Review on subjects such as economic growth and income distribution, which also use empirical data. The National Bureau of Economic Research set a whole day apart in 1998, the "National Security Day," to discuss pensions and drew on experts from different fields.

\section{SCIENCE AND CRYPTO-SCIENCE}

If the social sciences, including economics, are regarded as a "soft" technology compared with the "hard" technology of the natural sciences, development studies have been regarded as the soft underbelly of "economic science". I have heard it being equated to Economics minus Logic. In the attempt to emulate the colleagues practising "hard" economics, we have seen that mathematical methods are brought to bear on issues for which they are not appropriate.

In his Romanes Lectures, Sir Isaiah Berlin illustrates how what was once revolutionary doctrine has become Establishment doctrine, by Turgenev's Fathers and Children.

The victorious advance of quantitative methods, belief in the organisation of human lives by technological organisation, reliance on nothing but calculation of utilitarian consequences in evaluating policies that affect vast numbers of human beings, this is Bazarov, not the Kirzanovs. The triumphs of the moral arithmetic of cost effectiveness which liberates decent men from qualms, because they no longer think of the entities to which they apply their scientific computations as human beings...this today is rather more typical of the establishment than of the opposition.

Growing concern with social objectives: employment, poverty, women, equality, the environment has led in the past to calls for the "dethronement of GNP" which (erroneously) has been regarded as an economic objective. But the fault in the preoccupation with GNP was excessive attention to a simple quantitative index, irrespective of the valuations implicit in its sets of weights, i.e., of its composition, distribution, and the manner in which it was produced. The danger is that the same fault is repeated when simple indexes are constructed for social and human objectives. The proportion of the GNP earned by the bottom 40 percent, or the Gini coefficient, or the Human Development Index of the United Nations Development Programme's Human Development Reports are just as inadequate, and, if used only by themselves, just as misleading measures of what we are getting at when we try to eradicate poverty or reduce inequality, or remove unemployment, as GNP is an inadequate measure of productive capacity or economic welfare. 
Inequality of income distribution touches only a small portion of the vast, multidimensional problem of inequality. There is also inequality of ownership of assets, of access to assets and to earning opportunities, of satisfaction from work, of recognition, status, prestige, of ability to enjoy consumption, of access to power, of participation in decision-making, of freedom of choice, and many other dimensions. The call for greater equality, for a genuine community of equals, cannot be answered simply by measures that reduce the Gini coefficient or any other simple measure of inequality, which are inadequate even in expressing what concerns us in grossly unequal income distribution. It is possible to envisage a technocratic society, in which decisions are highly centralised and in which a few enjoy the satisfactions from power and creativity, while the many carry out boring or disagreeable tasks, or are unemployed, in a hierarchic structure and in which the Gini coefficient is zero, or in which at least there is no poverty. Kurt Vonnegut describes vividly such a society in his novel Player Piano. The materially satisfied but otherwise deprived underclass eventually rebel.

The danger of research in economics that attempts to emulate the "hard" sciences is that it selects the measurable and neglects the rest: only what can be counted counts, or even exists. (A secondary danger where statistics are very unreliable is to say "any figure is better than none".) Some of the most important obstacles to the eradication of poverty and the reduction of gross inequality lie in areas in which measurement is still very difficult or perhaps impossible. Among these are the following:

1. Unwillingness of governments to grasp the political nettles: land reform, tax reform, labour mobilisation, widening access to education and health services.

2. Linked with these élitism, nepotism, corruption.

3. Behind these again, various forms of power concentration in the form of oligopoly and monopoly: the power of large landowners, of big industrialists, of multinational corporations.

4. In a different field but sometimes equally disruptive, the power of organised labour unions and the obstacles to an incomes and employment policy that would create full employment without inflation.

5. Restricted access to educational opportunities, the imbalance in education and the resulting job certification that both reflects and reinforces the unequal structure of power and wealth.

6. Weak entrepreneurship and defective management and administration of public enterprises, private firms, the civil service, and some NGOs.

7. Lack of coordination between central government and regional, local, and project administrations. Too many countries are better on planning than on administration and implementation. 
8. The weakness of the structure, area of competence, recruitment, training, and administration of the UN Agencies charged with development, combined with a frequently narrowly technocratic approach, encouraged by the location, origin, and organisation of these Agencies and their politically "non-controversial" approach.

9. Finally, there are the terrible facts of mass slaughter of ethnic or religious minorities (often entrepreneurial and therefore hated) and political opponents, torture, imprisonment without trial, expulsion, and the vast sums spent on armies and the police and other horrors.

The list is not exhaustive but merely illustrative. It shows that the temptation to select the quantified and quantifiable at the expense of other, possibly more important areas reinforces political reasons for avoiding these problems and strengthens the vested interests that benefit from the status quo.

In a famous passage in Value and Capital John Hicks wrote that the assumption of perfect competition must be retained, or else the whole of economic theory would be a wreck. In his later days he regretted this and turned to a plea for a more realistic economics; but the priority of preserving an abstract, theoretical structure that yields to techniques over understanding the real world has permeated economics. Equilibrium analysis takes a central place although its lack of realism is generally recognised. Amartya Sen has pointed out that the use of equilibrium-based reasoning is subject to criticism. In particular, questions should be asked about its (1) existence, (2) uniqueness, (3) stability, and (4) efficiency.

Equilibrium may not exist. Even if it does exist, it may not be unique. Even if it exists and is unique, it may not be stable. And it may exist, be unique and be stable, but be inefficient in the sense of not achieving Pareto optimality. As Sen goes on to say, frequently the mere presence of competition is taken to entail the existence, uniqueness, stability, and efficiency of a general equilibrium. The difficulties of equilibrium economics are not primarily with the idea itself. They lie in the way the idea is applied. Among the critics of the competitive equilibrium approach to economics have been John Kenneth Galbraith and Janos Kornai, but their writings have not been accepted by the profession.

Similarly, the rejection of the assumption of increasing returns, ubiquitous in reality, by equilibrium analysts has made economics lose touch with reality. The importance of increasing returns has been recognised by great minds like Adam Smith, Allyn Young, Piero Sraffa, and Nicholas Kaldor, but has not found the place it deserves in the analysis of mainstream economists, because the formal analytical apparatus is absent.

In development economics the important question is: What are the springs of development? Many would stress the importance of entrepreneurial and managerial motivation and attitudes, of education of the right kind, and of appropriate 
institutions. But we do not know what characteristics make for the social selection of an innovating, entrepreneurial group, while many papers are written on years, months, days, and hours of schooling or the number or proportion of engineers and scientists. Neither innate characteristics nor education nor religion can explain why some societies, at certain periods, are better and quicker at innovating than others at other times. Innate characteristics are distributed according to normal distribution curves. The level of scientific education is quite high in many societies, such as India, in which innovation is poor, and vice versa; and all kinds of religion besides Protestantism have proved to be consistent with innovative behaviour: Roman Catholicism in Austria and Malta, Hinduism in East Africa, Confucianism and Buddhism in East Asia. What we need is an explanation of why, in some societies, with the right education, innate characteristics, and religion, the ablest and fittest, the "Best and the Brightest," the creative innovators are not attracted to production and business but, instead, to politics, universities or the civil service.

At the end, we must confess that we cannot answer the most important question in development economics, that we do not know what causes successful development. But we must try to resist the temptation to which so many have yielded, to behave like the drunk who has lost his key and looks for it not where he dropped it but under the street lamp-because this is where the light is. 